\title{
A adoção do princípio da função social do direito de propriedade pela Constituição brasileira de 1946
}

\author{
Eliardo França Teles Filho* \\ eliardofteles@yahoo.com.br
}

\section{RESUMO}

O artigo trata da contradição entre a existência de um dispositivo constitucional condicionando o direito de propriedade à função social e à prática administrativa e jurídica no Brasil, que parece orientar-se por uma visão absoluta do direito de propriedade. O estudo toma por base os debates dos constituintes de 1946, que optaram por adotar a função social daquele direito por motivos, paradoxalmente, contrários a sua subordinação à função social. Os dados mostram que os constituintes manipulavam tecnicamente bem os institutos jurídicos relativos à propriedade e que estes tinham importância na disputa por qual redação deveriam dar ao dispositivo constitucional.

Palavras-chave: História do direito; função social da propriedade; Constituição Federal de 1945.

The adoption of the principle of the social function of law property by the 1946 Brazilian Constitution

\begin{abstract}
The article deals with the contradiction between the existence of a conditional device, conditioning the property right to a social function and the administrative and juridical practice in Brazil that seems to be guided by an absolute view of the property right. The study bases on the 1946 constituents that opted for adopting the social function of that law for motives, paradoxically, opposed to its subordination to the social function. The data show that the constituents manipulated technically well the juridical institutes related to the property and that had importance in the dispute for the type of writing should be given to the constitutional device.
\end{abstract}

Key words: Law History, land social function, 1946 Federal Constitution.

\footnotetext{
* Mestrando do curso de Direito e Políticas Públicas do Centro Universitário de Brasília (UniCEUB); bolsista do Programa UniCEUB/CAPES/PROSUP.
} 


\section{INTRODUÇÃO}

Este artigo analisa as razões da adoção do princípio da função social do direito de propriedade pelos constituintes que elaboraram a Constituição de 1946. Além disso, compara a impressão que aquele texto dá e sua repercussão na técnica e na dogmática jurídica. Com isso, lança luz sobre o porquê de nunca ter havido uma reforma agrária no Brasil, apesar de todas as nossas constituições aparentarem ser favoráveis à mesma.

A primeira parte do artigo coloca o problema em termos de aparente contradição entre o texto constitucional de 1946, o primeiro a esboçar o verdadeiro princípio da função social do direito de propriedade, e as ações estatais subseqüentes referentes à reforma agrária. A segunda parte problematiza a contradição no do campo jurídico, mostrando que tampouco os manuais de direito e os procedimentos expropriatórios adequaram-se à diretriz constitucional. $\mathrm{Na}$ terceira parte, apresentamos o resultado de uma pesquisa sobre os debates dos constituintes sobre a adoção ou não do princípio da função social. Veremos que as razões dos constituintes permitem superar a contradição aparente e compreendê-la como o desenvolvimento normal do uso que os constituintes fizeram do princípio. A quarta parte trata de como o desenho que os constituintes deram àquela diretriz constitucional implicou a sua anulação enquanto instrumento para a implementação de uma reforma agrária. Dito de outro modo, o princípio se converteu em obstáculo à reforma. Ao final, apresentamos algumas considerações que podem servir para aclarar as relações entre o direito, de um lado, e a economia e a sociedade, de outro, e revelar algo sobre o pensamento jurídico do Brasil.

\section{O PROBLEMA: CONTRADIÇÃO ENTRE O TEXTO CONSTITUCIONAL E A INVIABILIDADE DA REFORMA AGRÁRIA}

A preocupação que deu origem ao artigo surgiu do estranhamento diante das dificuldades que um país tão extenso como o Brasil encontra em realizar reforma agrária que responda de maneira adequada às necessidades de boa parte das populações rural e urbana brasileira por justiça social, igualdade e inclusão. Mais do que isso, a implantação da Reforma agrária ampla poderia contribuir para a solidificação da economia capitalista no Brasil, na medida 
em que geraria um segmento de pequenos proprietários rurais, importante força na superação de entraves pré-capitalistas que naquele tempo ainda sobreviviam no Brasil.

Com base no ponto de vista jurídico predominante em nossa cultura, segundo a qual os problemas sociais são solucionáveis pura e simplesmente pela legislação ${ }^{2}$, a Constituição de 1946 já continha mecanismos suficientes para a implantação daquela reforma: a subordinação do direito de propriedade a sua função social. É a estes mecanismos que, neste artigo, damos o nome de princípio da função social do direito de propriedade.

Este princípio foi inscrito nos artigos 141, § 16, e 147 daquela Constituição. O primeiro, inserido no capítulo dos direitos fundamentais, garantia o direito de propriedade ao mesmo tempo em que permitia a desapropriação por interesse social mediante prévia e justa indenização em dinheiro, além das modalidades já reconhecidas nas constituições anteriores de desapropriação por necessidade e/ou utilidade pública. O segundo, no título da ordem econômica e social, condicionava o uso da propriedade ao bem-estar social e permitia a distribuição da propriedade por meio de lei que seguisse o princípio do artigo 141, § 16. Como se vê, os mecanismos tanto se referiam ao direito de propriedade como à propriedade.

Com esses mecanismos, o Estado parecia bem aparelhado para realizar políticas públicas visando ou à redistribuição de terras improdutivas, ou ao desestímulo da propriedade especulativa de terras. Mais do que isso, parecia estar obrigado a fazer a reforma agrária. Dado o grande número de terras improdutivas no país naquele tempo, era de se esperar que, com aquele princípio constitucional chegaríamos mais perto da justiça social (por meio da distribuição de um fator de produção que, teoricamente, permitiria melhores oportunidades econômicas a grupos sociais até então marginalizados) e do desenvolvimento econômico (por meio do estímulo a que os proprietários fizessem uso produtivo de suas terras, ou as vendessem a quem quisesse fazê-lo). Em todo caso, os mecanismos que conformavam o princípio da função social do direito de propriedade contribuiriam para a formação de uma classe de pequenos proprietários no Brasil.

\footnotetext{
${ }^{2}$ Avaliação parecida pode ser encontrada em diferentes autores e momentos de nossa história. Cf. URUGUAI, Visconde do. Ensaio sobre o direito administrativo. p. 453, nota 249: "Há muita gente que crê que a palavra liberdade é mágica e opera por si só todos os melhoramentos. Decretada a liberdade está tudo remediado”. A mesma crítica aparece em discurso de Hermes Lima, na Assembléia Constituinte de 1946, de que ora tratamos: "Essa tendência, Sr. Presidente, a mim me parece, vem do sentimento, de resto ilusório, de que, incorporando-se à Constituição um dispositivo, adquire ele, por força de sua natureza constitucional, o poder de realizar-se [...]” NOGUEIRA (2005, p. 386).
} 
Ocorre que, apesar da adoção do princípio da função social do direito de propriedade, nada daquilo que seria de se esperar da adoção de um princípio como esse ocorreu. Ainda hoje, apesar de estarmos há sessenta anos sob o regime constitucional da propriedade subordinada a sua função social, pouco se fez pela reforma agrária, seja em termos de políticas públicas consistentes, seja em termos da elaboração de leis que a implementassem efetivamente, se é que uma lei tem esse efeito.

Ao contrário, os efeitos daquela disposição constitucional foram bem outros. Foi na vigência daquela Constituição que o então presidente João Goulart pretendeu dar início à reforma agrária no Brasil, visando, não à abolição da propriedade, mas à "integração da população do campo à economia de mercado, gerando assim uma nova demanda para os produtos industriais” (FAUSTO, 2003, p. 449) ou seja, uma reforma agrária de molde eminentemente capitalista, que tencionava constituir uma camada social de pequenos proprietários. O resultado foi um golpe de Estado, em cujo discurso figurava a alegação de defesa da ordem constitucional firmada em 1946, ameaçada pela reforma agrária de João Goulart (SKIDMORE, 1982, p. 363). Aparentemente a ordem constitucional era ambígua: ao mesmo tempo em que endossava a função social da propriedade, não comportava a realização de reforma agrária, nem em moldes capitalistas.

\section{O PROBLEMA: A AMBIGÜIDADE NOS MANUAIS}

A ambigüidade torna-se mais impressionante se observarmos como foi a recepção da função social da propriedade pela dogmática jurídica. Pesquisando manuais bem posteriores à Constituição de 1946, percebemos que a função social da propriedade não fora absorvida por alguns dos principais juristas brasileiros.

Foram consultados nesta pesquisa, três manuais de direito privado cujos autores desfrutavam de bastante prestígio entre os professores e os alunos de direito civil de nossas faculdades. A intenção foi observar se os autores haviam mudado a forma como conceituavam a propriedade depois da adoção da função social, ou seja, se em razão da subordinação constitucional do direito de propriedade a uma função social, os autores passaram a conceituá-lo como um direito que implicasse deveres do proprietário para com a coletividade. Também foi consultado um administrativista, Hely Lopes Meirelles, a fim de pesquisar qual foi o impacto da 
adoção da função social da propriedade na doutrina administrativa do procedimento expropriatório. A seguir veremos sucintamente o resultado da pesquisa.

No primeiro dos manuais de direito privado, cujo autor é Sílvio Rodrigues, o direito de propriedade é tratado como um "liame que se estabelece entre o proprietário e a coisa que se encontra em seu domínio [e] vincula, de um certo modo, todas as pessoas do universo" (RODRIGUES, 1997, p. 74, grifo nosso). O autor, a despeito da transformação constitucional do direito de propriedade em um direito ligado a deveres, dá um conceito digno do liberalismo do século XIX, chegando a dar um poder metafísico àquele direito: o poder de vincular todas as pessoas do universo. Além dessa definição arcaica, e contrária à Constituição, notamos no texto daquele autor que o conteúdo é praticamente o mesmo há décadas, e que, a cada mudança constitucional, o autor apenas acrescenta algumas notas de rodapé, quase nada alterando quanto ao corpo do texto.

Outro autor de manuais consultado foi Washington de Barros Monteiro, que também adota viés ideológico contrário à concepção do direito de propriedade ligado a uma função social. A título de exemplo do conteúdo de suas explicações sobre a propriedade, citamos a seguinte definição: a propriedade é:

uma necessidade econômica para as sociedades civilizadas e que se impõe ao legislador e ao jurista. Seus inimigos, porém, existirão sempre, fazendo coro com Proudhon, para quem ela era um roubo, pretendendo assim uma noite de São Bartolomeu para todos os proprietários. (MONTEIRO, 1999, p. 79, grifo nosso).

O autor identifica civilização e sociedade capitalista, universalizando a necessidade típica de países capitalistas. A propriedade efetivamente é uma necessidade em sociedades capitalistas, porém, não é uma necessidade para todas as nações civilizadas, nem civilização é igual a capitalismo. Este é uma escolha de cada sociedade, a qual pode escolher viver segundo outro sistema, como os russos optaram no início do século XX. Por outro lado, o autor recorre a imagens históricas, a fim de estigmatizar os movimentos sociais que lutam pela modificação do direito de propriedade, sem lutar por sua supressão. Dessa forma, o autor justifica sua oposição à assimilação da função social do direito de propriedade, e mantém sua intransigente oposição à uma disposição constitucional. 
O terceiro manual, escrito por Caio Mário da Silva Pereira, chega a trazer subtítulo com o pomposo nome de "Sociologia da propriedade", no qual considera que desde a Constituição de 1946, todas as nossas constituições inscreveram a "subordinação do uso da propriedade ao bem-estar social”. Para esse autor, a partir da Constituição de 1946, a ordem jurídica tinha o seguinte posicionamento:

embora reconhecendo o direito de propriedade [...] abandonou a passividade que guardava ante os conflitos de interesse e passou a intervir, séria e severamente, no propósito de promover o bem comum que é uma das finalidades da lei, e ainda a assegurar a justa distribuição da propriedade com igual oportunidade para todos. (PEREIRA, 2000, p. 63-64, grifo nosso).

Fica a questão de saber o que o autor entende por “intervenção séria e severa”, já que uma das razões pelas quais os próceres do movimento de 1964 alegaram ter que derrubar o presidente é que este pretendia “intervir séria e severamente” na propriedade, o que seria inconstitucional. Além disso, não tenho notícia de nenhuma intervenção na propriedade nesses termos antes da década de 90. Mesmo aí, é só com muita boa vontade que se pode falar em “intervenção séria e severa”. Parece que este autor padece daquele problema que citamos na primeira nota de rodapé deste trabalho: pensar que a inscrição de uma palavra ou um texto na constituição é condição suficiente para sua materialização.

Pois bem, apesar desse autor entender que aquela constituição firmou uma tendência progressista quanto ao direito de propriedade, paradoxalmente, continua definindo-o como o “direito de usar, gozar e dispor da coisa”, retomando a clássica definição romana do dominium est jus utendi et abutendi, tão cara à concepção liberal de propriedade (PEREIRA, 2000, p. 67). Portanto, mesmo sendo simpático à subordinação do direito de propriedade a um dever para com a sociedade, o autor continua a conceituá-la segundo a fórmula romana, típica da concepção liberal clássica.

No direito administrativo ${ }^{3}$, a repercussão não foi maior. A pesquisa no livro de Hely Lopes Meirelles revelou que a função social do direito de propriedade foi assimilada a um conjunto de técnicas jurídicas denso e intransponível que torna o procedimento expropriatório

\footnotetext{
${ }^{3}$ Usamos a formulação da Escola Sociológica Francesa, segundo a qual todo pensamento é social, o que nos permite observarmos a repercussão do instituto da função social em toda a dogmática jurídica, com base apenas em alguns autores-chave do campo jurídico.
} 
totalmente inadequado aos fins sociais que todas as constituições, desde 1946, reservam ao direito de propriedade. A função social não levou à adoção de procedimento expropriatório significativamente diferente dos já existentes. As poucas modificações feitas podem tê-lo tornado mais complicado do que os demais. Assim, por exemplo, a desapropriação para fins de reforma agrária é privativa da União e depende de decreto do Presidente da República. Um município pode desapropriar terras para estabelecer um distrito industrial, mas não pode fazê-lo para fins de reforma agrária (MEIRELLES, 1998, p. 495).

Esta pesquisa preliminar aumenta nossa perplexidade diante da inadequação entre a constitucionalização da função social do direito de propriedade e a ação política posterior. Agora, trata-se do comportamento dos próprios juristas, que não absorvem a disposição constitucional, nem tentam recriar os conceitos e os procedimentos jurídicos existentes, em razão de uma determinação constitucional. Diante de uma inovação constitucional, tem mais força a técnica jurídica a que estão habituados e cuja permanência defendem com unhas e dentes, conforme vimos explicitamente em Washington de Barros. Passamos, assim, da impressão com a contradição entre o direito e a prática do Estado, para a perplexidade diante do comportamento dos juristas, que ficam surdos a um princípio constitucional.

A maneira pela qual conseguimos superar esta perplexidade foi recorrendo às razões dos constituintes para a subordinação do direito de propriedade a uma função social. A fonte que buscamos isso foi o livro de José Duarte, A constituição brasileira de $1946^{4}$. A seguir, mostramos alguns pronunciamentos dos constituintes sobre o assunto, a fim de descobrirmos se as razões que tinham em mente ao defender a função social explicam as ambigüidades em que o instituto foi envolvido, tanto pela ação política e administrativa posterior, quanto por sua interpretação e assimilação pela doutrina jurídica.

\section{A SUPERAÇÃO DA AMBIGÜIDADE: AS RAZÕES DOS CONSTITUINTES DE 1946 PARA A ADOÇÃO DA FUNÇÃO SOCIAL}

O relato de José Duarte sobre os debates referentes à adoção do princípio da função

\footnotetext{
${ }^{4}$ Este livro traz um resumo dos discursos dos constituintes com trechos inteiros de transcrições e é apontado na coleção “Constituições do Brasil”, organizada por Walter Costa Porto, como fundamental para a compreensão da Constituição de 1946.
} 
social do direito de propriedade mostra que havia diversas posições entre os constituintes. Provavelmente, algumas estavam ligadas a outros debates e podiam significar o uso da discussão sobre direito de propriedade para impor posições estratégicas a partir das quais uns atores pudessem negociar posturas favoráveis com outros atores sobre temas diretamente de seu interesse. Contudo, para este trabalho vamos considerar apenas a discussão sobre o direito de propriedade e a desapropriação por descumprimento da função social, que é o nosso assunto. Nem poderia ser diferente, dadas as dimensões desse trabalho.

Pois bem, a primeira coisa que se constata no livro de Duarte é a diversidade de posições. Alguns constituintes que entendiam não ser necessária a inscrição do princípio para que houvesse possibilidade de desapropriação por interesse social. Para esses, a modalidade de desapropriação estaria compreendida na categoria de utilidade pública ${ }^{5}$. Outros achavam que a adoção do princípio seria desnecessária visto que o Brasil tinha terras em excesso. Não precisaria, portanto, adotar princípios limitadores do direito de propriedade por serem estranhos à realidade brasileira. O ex-presidente Artur Bernardes, que se incluía neste último grupo, defendia a tese de que no Brasil não havia latifúndios, logo não haveria necessidade de desapropriar terras para a possível reforma agrária. Afirmava que o interesse social poderia ser subsumido ao interesse público, caso fosse necessário limitar o direito à propriedade. Declarou-se, por isso, contrário à adoção do princípio da função social da propriedade (DUARTE, 1947, p. 46-47). O que importa ressaltar no posicionamento desse ex-presidente é o seu viés anti-reforma agrária, mais do que os meios pelos quais ele pretendeu impedi-la. Posteriormente, veremos que dificultar a reforma agrária era quase consenso, os constituintes apenas diferiam nos meios pelos quais pretendiam fazê-lo. Para Artur Bernardes, o meio mais conveniente era não constitucionalizar o princípio da função social da propriedade.

Os constituintes que defendiam a adoção do princípio tinham como preocupação predominante deixar à legislatura ordinária a menor margem de ação possível para a flexibilização do direito de propriedade. Para eles a constituição deveria exprimir claramente as possibilidades de desapropriação, inclusive a por interesse social, tornando-a uma restrição ao uso da propriedade e não “ao direito da propriedade em si”, segundo expressão atribuída ao constituinte Arruda Câmara (DUARTE, 1947, p. 45). Outra preocupação era a de preservar os

\footnotetext{
${ }^{5}$ Assim, por exemplo, Mário Masagão e Hermes Lima. Cf. DUARTE, José. A Constituição brasileira de 1946: Getúlio, o sujeito oculto. São Paulo: M. Fontes, 2005. p. 38-39, 41, 48.
} 
conceitos de utilidade e necessidade pública, mantendo seu conteúdo intacto frente às modificações sociais. Para isso, era preciso que a Constituição previsse a terceira possibilidade de desapropriação, para que o legislador ordinário ou os juristas não deparassem com a possibilidade ou a necessidade de modificarem aqueles conceitos. Assim, por exemplo, Ferreira de Sousa, para quem "as expressões 'necessidade e utilidade pública' têm sentido fartamente conhecido e absolutamente inalterável no campo do direito” (grifo nosso) e enumerava esses sentidos, referido-os sempre ao Estado. Para que fosse possível a modalidade de desapropriação sem que o interesse fosse estritamente do Estado, seria preciso criá-la (DUARTE, 1947, p. 3738). Este pronunciamento mostra a valorização da técnica jurídica como um bem em si mesmo, e não como um instrumento para a obtenção de outros bens. A técnica jurídica estrita era vista como um bem a ser preservado e respeitado. Assim, adotar uma terceira modalidade de desapropriação era condição para a manutenção da técnica.

A intenção de esvaziar ao máximo o poder da legislatura ordinária ao introduzir o princípio da função social aparece em discurso atribuído ao constituinte Soares Filho:

\footnotetext{
Se votarmos um texto pelo qual seja permitido entrar-se no conteúdo da propriedade, chegaremos, pela legislação ordinária, inclusive, até a conceituação de propriedade como função social, o que poderá atingir até a sua abolição, porque não haverá barreira constitucional impedindo que ela assim seja considerada.

Por isso, entendo, consoante a média das opiniões refletidas nesta reunião, que não podemos votar um texto em que a propriedade seja considerada como plena, da mesma forma que não podemos votar um dispositivo que permita a definição do seu conteúdo pela lei ordinária, o que permitira os resultados a que se refere [Soares Filho].

Daí inclinar-se [Soares Filho] para qualquer redação semelhante à da Constituição de 1934, que garante o direito de propriedade, desde que não seja exercido contra o interesse social ou coletivo. (DUARTE, 1947, p. 49).
}

Notemos que inscrever o princípio da função social na Constituição era impedir que o legislador o fizesse, dando porventura maior ênfase a seu aspecto “social” do que aquela Assembléia estava disposta a permitir.

Outro constituinte, Prado Kelly, referiu-se à reforma agrária para defender que não fosse dada à legislação ordinária nenhuma margem para estabelecer outra forma de intervenção na propriedade que a desapropriação com indenização. Para ele, se deixassem à legislatura 
ordinária o poder de normalizar o conteúdo da propriedade, corria-se o risco de que a reforma agrária se fizesse por meio do confisco (Duarte, 1947, p. 42). Sousa Costa entendia que a definição constitucional do direito de propriedade era condição para que o Brasil recebesse os investimentos estrangeiros de que tanto precisava. Para ele ninguém aplicaria seus recursos em um país “onde o direito de propriedade está na dependência do legislador ordinário” (Duarte, 1947, p. 43).

Os argumentos dominantes pela adoção do princípio da função social são, portanto, no sentido de restringir, ao máximo, o poder do legislador ordinário de legislar sobre o conteúdo do direito de propriedade. Os constituintes lutaram pela inclusão do princípio da função social da propriedade para impedir as restrições à propriedade, e não o contrário.

A adoção da segunda inovação referente à propriedade por aquela Constituição esclarece a intenção dos constituintes com relação ao direito de propriedade. Trata-se da expressão “indenização em dinheiro”, como complemento à restrição do poder do legislador comum. Esta proposta teve o sentido de complementar a garantia da propriedade contra a intervenção do Estado, estabelecendo uma norma rígida a ser obedecida pela desapropriação, prevista como única medida possível de limitar legalmente o direito de propriedade. Ao constitucionalizar a intervenção na propriedade por motivo de interesse social, os constituintes determinaram que isso se daria por meio do mecanismo da desapropriação a qual deveria ser prévia, justa e “em dinheiro”.

Quem propôs a emenda com a expressão “em dinheiro” foi Arruda Câmara, para quem o direito de propriedade era um direito natural, “o mais importante para o homem, depois do direito de liberdade individual”. Sua intenção ao propor a cláusula restritiva mencionada, foi “acautelar os interesses do proprietário, quando o Estado, por dificuldades financeiras ou abuso de autoridade, entender efetuar os pagamentos em apólices ou títulos” (Duarte, 1947, p. 44-45). Assim, colocava-se o interesse social, aquele que permitiria que uma propriedade fosse desapropriada em benefício da coletividade, em posição de subordinação ao interesse individual do proprietário, já que este só seria limitado quando as circunstâncias financeiras o permitissem. Na falta de dinheiro para o Estado realizar política redistributiva, o interesse do proprietário prevaleceria sobre o da coletividade, segundo a proposta de emenda de Arruda Câmara. 
Proposta parecida foi apresentada por Aliomar Baleeiro, que defendia a expressão "em moeda corrente". Para esse constituinte, jurista de renome, posteriormente ministro do Supremo Tribunal Federal, a emenda funcionaria como reação às ações do governo contra a propriedade. Ele se referia a um decreto-lei expedido meses antes por meio do qual o governo abrira a possibilidade de pagar metade do valor de desapropriações por interesse público com títulos. É no discurso dele que aparece, de maneira mais cortante, embora sutil, a intenção de preservar os interesses e os direitos dos proprietários. Pretendendo que o direito de propriedade sempre fora limitado pelos interesses sociais e pelo ideal de justiça de cada época, ainda que isso se desse silenciosamente, o constituinte recorreu à abolição dos escravos para justificar suas posições:

Se houvesse necessidade de demonstrar uma verdade tão evidente quanto esta [de que o conteúdo do direito de propriedade está relacionada com os interesses sociais e com o ideal de justiça de cada época] tantas vezes repetida na história, poderíamos lembrar o que se passou a 13 de maio de 1888. Até aquela data, era legal, honesto e moral na concepção dos homens do tempo que um homem pudesse ser propriedade de outro. E o Estado amparava sua receita na propriedade escravocrata, cobrando imposto sobre os cativos. No dia 13 de maio, certa maioria ocasional no Parlamento decidiu que a propriedade sobre o homem deveria desaparecer. $E$, naquela época profundamente agrária de mentalidade inteiramente diferente da nossa, fez-se a expropriação de parte considerável dessa propriedade, sem um vintém de indenização a quem quer que fosse. Poderia multiplicar os exemplos, mostrando que todas as leis, em regra, limitam a propriedade, de acordo com as necessidades e o interesse social e até, como já mostrei, segundo a concepção de justiça. (DUARTE, 1947, p. 40)

Este constituinte tinha proposto uma emenda permitindo a limitação da propriedade por interesse social e usou o exemplo da abolição dos escravos para mostrar que seria melhor disciplinar constitucionalmente a hipótese de desapropriação por interesse social do que silenciar a respeito e permitir que "certa maioria ocasional no Parlamento" viesse a fazê-lo com prejuízo para os proprietários. Como se sabe, a Constituição de 1824, sob cuja ordem vigorou o regime de propriedade escrava, silenciava a respeito dessa forma de propriedade, de modo que ao lembrar o evento da abolição dos escravos, o constituinte conclamava seus pares a não permitir que, novamente, o silêncio da carta magna permitisse semelhante confisco "sem um vintém de indenização". 
Ao reduzir o longo e penoso processo político, econômico, social e cultural que levou à abolição da escravidão a “uma decisão tomada por certa maioria ocasional”, Aliomar Baleeiro parece padecer daquela visão idealista segundo a qual a letra da lei se transforma em realidade por si só. Contudo, Baleeiro não era nenhum ingênuo. Como já dissemos, era jurista e político experimentado. A redução que faz do longo processo da abolição a um ato de vontade do parlamento, revela, não um desconhecimento, mas uma visão de mundo na qual a política e o direito tem prioridade sobre a sociedade, a economia e a cultura.

Aliomar Baleeiro usou o exemplo da Constituição de 1824, que, ao silenciar sobre a propriedade de escravos, permitiu que a "maioria parlamentar ocasional”, voluntarista, acabasse com a mesma propriedade. Fez isso para defender que a Constituição de 1946 não poderia cometer o mesmo erro, mas deveria disciplinar em tudo o direito de propriedade, para salvá-lo das maiorias ocasionais voluntaristas. Ora, naquela época, era notório, que a abolição foi, em boa parte, o resultado de um processo econômico e social que levou o Parlamento a não ter outra saída a não ser proclamá-la. Simplificando, podemos dizer que o ato do Parlamento foi condicionado pelas mudanças econômicas, sociais e culturais, e não o contrário. Baleeiro não ignorava isso.

Porém, ele defendia que a Constituinte de 1946 não cometesse o mesmo erro, ou seja, defende que a Assembléia adotasse um texto que não deixasse o Parlamento sujeito aos influxos das transformações econômicas, sociais e culturais. Defendia a possibilidade de um dispositivo constitucional barrar aquelas transformações. Em última instância, defende a predominância do jurídico sobre o econômico e o social.

Pode ser que a defesa destas posições pelos constituintes esteja em conexão com vários imponderáveis. Talvez, esses constituintes não acreditassem no que estavam dizendo; que fossem fervorosos defensores da reforma agrária, mas tinham que usar estes argumentos a fim de não assustar seus pares e aprovar a função social do jeito que fosse. Essa hipótese parece imponderável. Contudo, o que importa é que esses argumentos veiculavam, circulavam legitimamente na Assembléia e, no fim, prevaleceram, pois o texto da Constituição foi adotado com as modificações que os constituintes defenderam. Se circularam e geraram efeitos, não podem ser desprezados. 


\section{O OBSTÁCULO: EFEITOS JURÍDICOS DA ADOÇÃO DA FUNÇÃO SOCIAL DO DIREITO DE PROPRIEDADE PELA CONSTITUIÇẪO DE 1946}

Tratamos dos efeitos que o dispositivo da função social do direito de propriedade teve na dogmática jurídica, nas políticas públicas de reforma agrária, na política brasileira e na história do país. Veremos nas próximas linhas, como a forma que o princípio assumiu na Constituição converteu-o num adversário da desapropriação, sob o ponto de vista jurídico.

Colocar o princípio da função social na constituição, lado a lado e em equivalência com os conceitos de utilidade e necessidade pública significava dar àquele princípio a disciplina aplicável a estes conceitos; dar ao Estado, como único meio de promover a justiça social e o desenvolvimento no campo, o instrumento da desapropriação mediante indenização. Isso era aplicável, tradicionalmente, aos casos de utilidade e necessidade pública, isto é, quando o Estado toma para si bens de particulares. No entanto, a perda da propriedade por descumprimento da sua função social não era caso de o Estado tomar para si a propriedade alheia, mas de tomá-la de quem não a usasse e cedê-la a outros como forma de promover políticas de desenvolvimento, igualdade e justiça social. Em outras palavras, tratava-se de desapropriação em benefício da coletividade, e não em benefício do Estado. Por isso, o instrumento da desapropriação não se adequaria ao objetivo redistributivo, pois, ao exigir a indenização, vincula as políticas públicas à arrecadação financeira, deixa de ser redistributivo e passa a fazer mudar de mãos a propriedade, remunerando "justa e previamente" o expropriado, de forma que este não perderia nunca.

Ainda hoje, manuais de direito administrativo apresentam as três possibilidades de desapropriação em conjunto e sob o mesmo rito, embora distingam utilidade e necessidade públicas, de um lado, de interesse social, de outro. Hely Lopes Meirelles, por exemplo, comentando as possibilidades de desapropriação previstas na Constituição Federal de 1988, diz que "a necessidade pública surge quando a Administração defronta situações de emergência, que, para serem resolvidas satisfatoriamente, exigem a transferência urgente de bens de terceiros para o seu domínio e uso imediato". Por outro lado, "a utilidade pública apresenta-se quando a transferência de bens de terceiros para a Administração é conveniente, embora não seja imprescindível” (grifos nossos). Os termos coletividade ou social só surgem na doutrina do administrativista quando se quer definir o que é interesse social: 
O interesse social ocorre quando as circunstâncias impõem a distribuição ou o condicionamento da propriedade para seu melhor aproveitamento, utilização ou produtividade em benefício da coletividade ou de categorias sociais merecedoras de amparo específico do Poder Público. [...] O que convém assinalar desde logo, é que os bens desapropriados por interesse social não se destinam à Administração ou a seus delegados, mas sim à coletividade ou, mesmo, a certos beneficiários que a lei credencia para recebêlos e utilizá-los convenientemente. (MEIRELLES, 1997, p. 492-493, grifo nosso)

De maneira paradoxal, a possibilidade de desapropriação em benefício da coletividade é equiparada e submetida às mesmas regras daquelas feitas por interesse do Estado. Em outros termos, os constituintes protegeram os interesses dos proprietários contra o Estado, seguindo a tradição liberal, e contra a coletividade, seguindo a tradição autoritária e antidemocrática brasileira ${ }^{6}$. A mesma garantia constitucional contra a perda da propriedade para o Estado arbitrariamente, foi erigida contra a perda da propriedade por mau uso. Resumindo, a intervenção na propriedade por interesse social é que teve de submeter-se aos ritos da intervenção por interesse estritamente estatal.

Assim, vemos porque era tão importante a defesa da "inalterabilidade absoluta” da técnica jurídica, como a defendeu Ferreira de Sousa. Manter a técnica e a dogmática jurídica inalterável é uma forma de manter a configuração jurídica mesmo após mudanças constitucionais. No caso da função social do direito de propriedade, a desapropriação por interesse social foi submetida à técnica preexistente, com isso, adquiriu sentido oposto ao que literalmente diz. A determinação constitucional, aparentemente favorável à reforma agrária, se tornou contrária a isso a partir do momento em que foi submetida aos ritos “absolutamente inalteráveis” do direito administrativo. Se a técnica jurídica evoluísse com a prática, as disposições constitucionais, tão cuidadosamente urdidas pelos constituintes para manter o Parlamento longe do influxo da sociedade, poderiam ficar à mercê das interpretações dos juristas e das vontades de "maiorias ocasionais”.

Isso mostra que aqueles constituintes legislavam levando em consideração a técnica jurídica existente. Desse modo, no caso que estudamos, os constituintes reorganizaram as

\footnotetext{
${ }^{6}$ Segundo Octaciano Nogueira (2005, p. XXIX), o dilema das democracias brasileiras tem sido o de garantir que sejam democracias de minorias.
} 
categorias jurídicas existentes a fim de causar um efeito: que a propriedade fosse garantida contra as transformações sociais, econômicas e culturais do país. Por isso, uma mudança no sentido daquelas categorias, na técnica jurídica, poderia jogar água abaixo o arranjo de categorias que os constituintes erigiram em obstáculo à intervenção da sociedade na propriedade.

\section{CONCLUSÕES}

Os constituintes adotaram a categoria "interesse social” de uma forma que a esvaziou de seu conteúdo propriamente social. Assimilaram-na à categoria “utilidade pública”, de forma que as técnicas jurídicas para as duas desapropriações, que deveriam ser distintas, se uniformizaram. Para estabelecer esse arranjo, os constituintes utilizaram-se da técnica jurídica preexistente. Deste modo, a sobrevivência da intenção do dispositivo constitucional exigia a preservação daquela técnica. Ver a técnica jurídica como um valor em si mesmo, portanto, não foi falha do pensamento jurídico brasileiro, mas um modo de conter certos processos sociais e controlar as possibilidades de uso que os futuros intérpretes farão dos institutos. Portanto, a valorização da técnica em si mesma tem uso político, não é neutra.

Aqui, devemos fazer um comentário, porquanto tem sido dito que as interpretações ou os usos futuros de uma norma não devem preocupar-se com a intenção do legislador. E não devem mesmo. Contudo, algumas vezes o legislador deliberadamente manipula categorias jurídicas a fim de estabelecer uma previsibilidade, ou até uma vinculação, sobre as interpretações e usos futuros de suas disposições. Ora, a previsibilidade ou a vinculação só é operativa se o intérprete tentar se reduzir a um simples aplicador automático da técnica jurídica.

No caso que estudamos, a desapropriação por interesse social e a submissão do direito de propriedade a uma função social foram feitas deliberadamente, com base em técnica jurídica, à qual os intérpretes posteriores referiam suas conceituações, seus usos, suas elaborações teóricas ou práticas dos institutos. O efeito disso foi prender-se à intenção dos constituintes. Dito de outro modo, enquanto os intérpretes se movimentaram dentro da técnica jurídica, eles estiveram vinculados à mens legis dos constituintes. Apenas recentemente, um autor, em trabalho eminentemente político, notou o nó jurídico que foi o instituto da função social do direito de 
propriedade $^{7}$, a propósito da Constituição de 1988. Portanto, a alegação de que a interpretação é livre é defensável. Contudo, pode não ser viável se os juristas se posicionarem apenas como aplicadores transparentes da lei.

Por outro lado, a adoção da função social esteve ligada à tentativa de conter juridicamente algumas transformações econômicas, sociais e culturais no Brasil. Por meio da constitucionalização da função social, nos termos em que foi feita, os constituintes tentaram livrar o Parlamento dos influxos da sociedade e das pressões econômicas que poderiam levar a legislatura ordinária a realizar a reforma agrária. O resultado disso também foi visto aqui.

Quando as modificações estruturais e culturais da sociedade brasileira exigiram a ação estatal para a modernização das relações de trabalho e produção no campo, quando pressões sociais exigiram a transformação de camponeses em pequenos proprietários, o resultado foi que o sistema político travou, justamente no dispositivo constitucional da função social. Com isso, o Executivo não pôde responder às pressões sociais, e tentou passar por cima daquele dispositivo, interpretando-o além do que a técnica jurídica condicionada pelos constituintes permitia. O desfecho foi o golpe militar e o surgimento de outro modelo de Estado, interventor na economia e no campo, mas em cujo projeto também não estava a reforma agrária. Nesse sentido, a função social do direito de propriedade na Constituição de 1946 foi mais um capítulo na longa história da nossa democracia das minorias.

\section{REFERÊNCIAS}

DUARTE, José. A constituição brasileira de 1946: exegese dos textos à luz dos trabalhos da Assembléia Constituinte. Rio de Janeiro: Imprensa Nacional, 1947.

FAUSTO, Boris. História do Brasil. São Paulo: Edusp, 2003.

GRAU, Eros Roberto. A ordem econômica na Constituição de 1988: interpretação e crítica. 9. ed. São Paulo: Malheiros, 2004.

MEIRELLES, Hely Lopes. Direito administrativo brasileiro. São Paulo: Malheiros, 1998.

${ }^{7}$ Cf. GRAU, Eros Roberto. A ordem econômica na Constituição de 1988: interpretação e crítica. 9. ed. São Paulo: Malheiros, 2004. p. 307-308. 
MONTEIRO, Washington de Barros. Curso de direito civil: direito das coisas. 35. ed. São Paulo: Saraiva, 1999.

NOGUEIRA, Octaciano. A Constituinte de 1946. Getúlio, o sujeito oculto. São Paulo: M. Fontes, 2005.

PEREIRA, Caio Mário da Silva. Instituições de direito civil. Rio de Janeiro: Forense, 2000. v. 4.

PORTO, Walter Costa [Coord.]. Curso Constituições do Brasil: A Constituição de 1946. Brasília: Centro de Ensino à Distância, 1987. v. 5.

RODRIGUES, Sílvio. Direito civil: direito das coisas. 24. ed. São Paulo: Saraiva, 1997. v. 5.

SKIDMORE, Thomas. Brasil: de Getúlio Vargas a Castelo Branco (1930-1964). 7. ed. Rio de Janeiro: Paz e Terra, 1982.

Agradecimentos: gostaria de agradecer ao Professor Roberto Armando Ramos de Aguiar, que revisou este trabalho e incentivou sua publicação.

Prismas: Direito, Políticas Públicas e Mundialização

http://www.mestrado.uniceub.br/revistamestrado

Artigo recebido em 15/03/2006 e aceito para publicação em 22/04/2006

A revista Prismas: Direito, Políticas Públicas e Mundialização destina-se à publicação de artigos relacionados com a área jurídica, tem o propósito de difundir as reflexões dos pesquisadores, docentes, discentes, profissionais e estudantes da área de Ciências Jurídicas.

Os artigos são avaliados mediante processo de revisão por pares e deverão contemplar as reflexões que dizem respeito ao estudo do Direito, das Relações Internacionais e das Políticas Públicas. 